\title{
A versatile reactor for continuous monitoring of biofilm properties in laboratory and industrial conditions
}

\author{
M.O. Pereira' ${ }^{1}$, P. Morin ${ }^{1}$, M.J. Vieira ${ }^{1}$ and L.F. Melo ${ }^{2}$ \\ ${ }^{1}$ Centro de Engenharia Biológica-IBQF, Universidade do Minho, Braga, Portugal and ${ }^{2}$ Department of Chemical \\ Engineering, University of Porto, Portugal
}

2000/59: received 21 November 2000, revised 25 May 2001 and accepted 27 September 2001

M.O. PEREIRA, P. MORIN, M.J. VIEIRA AND L.F. MELO. 2002.

Aims: The understanding of the dynamics of surface microbial colonization with concomitant monitoring of biofilm formation requires the development of biofilm reactors that enable direct and real-time evaluation under different hydrodynamic conditions.

Methods and Results: This work proposes and discusses a simple flow cell reactor that provides a means to monitoring biofilm growth by periodical removing biofilm-attached slides for off-line, both non-destructive and destructive biofilm analyses. This is managed without the stoppage of the flow, thus reducing the contamination and the disturbance of the biofilm development. With this flow cell, biofilm growth and respiratory activity can be easily followed, either in well-defined laboratory conditions or in an industrial environment.

Conclusions, Significance and Impact of the Study: The reproducible and typical biofilm development curves obtained, validated this flow cell and confirmed its potential for different biofilm-related studies, which can include biocidal treatment.

\section{INTRODUCTION}

Biofilm can be defined at minima as a consortium of bacteria embedded in a polymeric matrix fixed on an immersed surface. This is mainly the case for well-controlled monospecies laboratory biofilms. In nature and in industrial environments, the structure and the composition of the fixed biomass are more complex, as they include all kind of particulate matter and upper animalcules in the food chain such as protozoa (Costerton et al. 1987; Block et al. 1993). Because biofilm formation is an ubiquitous phenomenon on surfaces in contact with liquids, it has multiple practical impacts, from dentistry to drinking water distribution to paper industry, that need to be studied.

In the last decade, attempts have been made to develop laboratory biofilm reactors that minimize heterogeneity of experimental conditions in order to make validation of biofilms data easier, and enable direct and real-time evaluation of bacterial colonization of submerged surfaces (Mittelman $e t$ al. 1992). Laboratory biofilm research may involve sophisticated techniques such as confocal laser microscopy, electrochemical

Correspondence to: P. Morin, Centro de Engenharia Biologica-IBQF, Universidade do Minho, Campus de Gualtar, 4700-057 Braga, Portugal (e-mail:perig@deb.uminho.pt). and piezoelectric techniques (Nivens et al. 1995). However, in industrial environments the use of this kind of procedures is usually quite impracticable. It is recognized (Ludensky 1998) that the most trustworthy industrial data are obtained with less advanced methods, either via continuous, on-line fouling monitoring techniques or indirect, off-line techniques, the latter generally including the removal of test surfaces for analysis (Jones and Bradshaw 1996). There are several types of biofilm reactors currently used in laboratory and field studies, each one with advantages and drawbacks. The two most important types of reactors for open continuous culture of biofilms are the annular reactors (Rototorque) (Chen et al. 1993) and the Robbins device (Gilbert and Allison 1993). They are fixed-support biofilm reactors that allow working in continuous flow system. The annular reactors are particularly expensive and the size of the studying surface area is limited (except in the laboratory version of the Rototorque). The flow must be stopped for slide removal and started again after closing the system in the Robbins device and in the industrial version of the Rototorque, hence exposing the remaining biofilm to sudden hydrodynamic changes (i.e. non-uniform conditions for biofilm growth), including hydraulic shocks.

The present work introduces a simple and non-expensive design for a flow cell reactor, which operates in vertical position in a continuous recycling mode, and provides controlled 
environmental conditions for the study of bacterial adhesion and biofilm development. It allows the study of biofilm processes under selected velocities to test different hydrodynamic conditions. Two important features of this flow cell reactor are: (i) it allows periodical sampling by removing colonized slides without stopping the flow, thus, diminishing the contamination and the disturbance of the biofilm; (ii) it is highly versatile, allowing different types of measurement techniques to be carried out on the samples, such as confocal laser scanning microscopy, respirometry, chemical analyses, thickness, etc. It also permits visual surveillance of biofilm formation. It was used to study biofilm development in laboratory applications and in an industrial plant through the circulation of real process water from a side stream connected to the white water circuit of a paper mill.

\section{MATERIALS AND METHODS}

\section{Flow cell reactor}

The flow cell reactor is presented in Fig. 1 in one of its version. It consists of a semicircular Perspex duct with several apertures on its flat face to fit adhesion devices. These devices are constituted by rectangular pieces (cassettes) of Perspex on which slides of the material to study, i.e. Perspex, stainless steel or any other material can be glued. Biofilm is formed on the slides that are in contact with the liquid circulating in the reactor. This can be a pure bacterial suspension, tap water or industrial process water. Each cassette can be removed separately without disturbing the biofilm formed on the others or stopping the flow. This is possible because outlet ports are disposed on the round face of the flow cell between each two adjacent slides that permit to deviate the circulating flow from the place where the reactor is opened (Fig. 1). The reactor can be built with different sizes of flow cells mounted in series or in parallel. It can work either as a plug flow reactor or as a continuously stirred tank reactor (CSTR) by means of a recirculation pump, with laminar or turbulent flow. In that case, residence time distribution measurements (data not shown) proved that the reactor can be considered as perfectly mixed (Brown and Fogler 1986).

\section{Reactor inocula}

The Gram-negative aerobic bacterium Pseudomonas fluorescens was used to produce a monospecies biofilm in laboratory tests. It was grown in a $1 \mathrm{~L}$ aerated and agitated glass vessel (fermenter 1) continuously fed a sterile nutrient solution. This culture was used to continuously inoculate a $3 \mathrm{~L}$ vessel

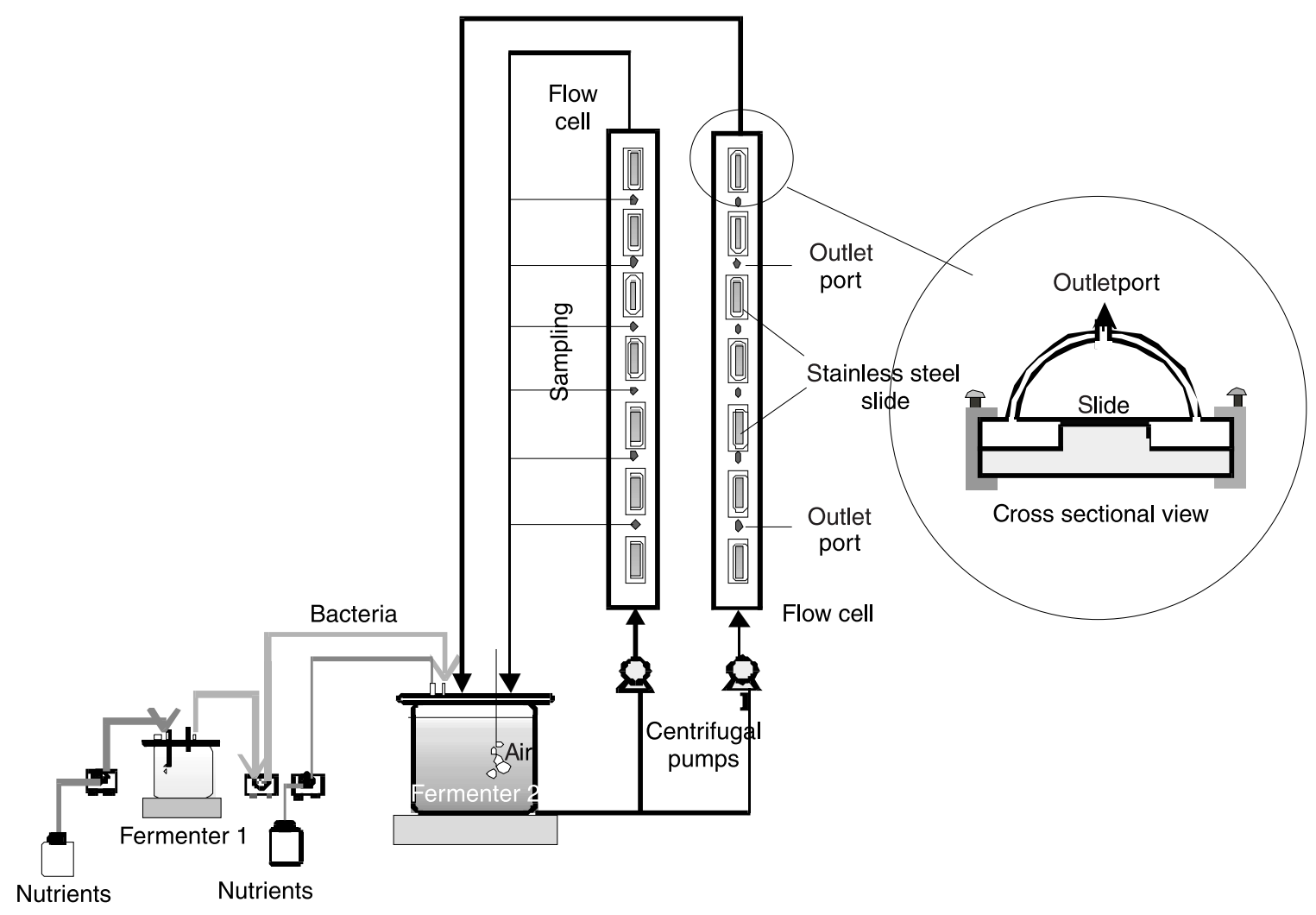

Fig. 1 Flow diagram of one version of the experimental system. Versions differed by the inoculum mode (see Materials and Methods) 
(fermenter 2) containing the same medium and diluted with filtered tap water. In this set-up as in the next one the reactor worked as a CSTR.

To study tap water biofilm, the fermenter system described above was replaced with two consecutive granular activated carbons (GAC) filter columns that were directly plugged on the laboratory water tap. The first GAC filter eliminated the free chlorine contained in the tap water, while the second was a biological activated filter furnishing continuous bacterial inoculum to the reactor.

For the experiments in industrial environment, the reactors were inoculated by the process water directly coming from the white water loop of a paper mill (stream entering the paper machine) and were operated without recirculation in a plugflow mode.

\section{Biofilm formation and reactor operation}

Biofilms were formed from the different inocula pumped into the reactors that worked under either laminar or turbulent flow regime. Periodically, slides were carefully removed under aseptic conditions and replaced with clean ones, without stopping the flow, and the attached biofilm collected for further analysis.

\section{Biofilm analyses}

The biofilm accumulated on the material surface (either Perspex or metal) was measured either by thickness, bacterial density or by biomass weight over time.

The thickness of the biofilms was estimated using a micrometer with the help of a microwatcher $(V S .-30 \mathrm{H}$, Mitsubishi Kasei Corporation (MKC) Research Centre, Yokohama, Japan) (Vieira et al. 1993).

Bacterial density was evaluated by scraping the biofilm in phosphate buffer and by treating the suspension either for cultivable bacteria or for total cells after dispersion of the

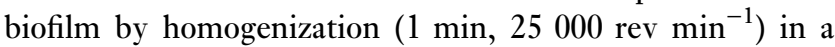
tissue homogenizer (IKA Labortechnik, Werke Gmbh \& Co., Post Fach, Sanfen, Germany). Cultivable bacteria, presented as $\mathrm{cfu} / \mathrm{cm}^{2}$, were estimated by plating the bacterial suspension in triplicate on R2A agar plates after proper dilution and by counting the colonies on the plates after $7 \mathrm{~d}$ at room temperature. Total cell density was given by filtering and dyeing an aliquot of the bacterial suspension with DAPI. The filter was then prepared and read under the microscope at a magnification of $\times 1000$.

The quantification of the mass accumulated on the slides was measured as the difference between the weight of the plate at $\mathrm{d} 0$ and the combined weight of the plate and the fixed deposit at the time of removal. For each experiment, the stainless steel plates were identified, air-dried until constant mass and weighed before being placed in the reactor. When removed from the reactor, the mass of the slide plus deposit was determined in the same conditions. The biomass was expressed in grams per $\mathrm{cm}^{2}$ surface area of the stainless steel plate. The results are the average of at least three measurements.

The cellular activity of the monospecies biofilm was also evaluated through oxygen consumption measurements after scraping and resuspending the biomass into a biological oxygen monitor (Yellow Spring Model 53, Yellow Springs Instruments Co., Inc., OH, USA). The oxygen uptake rates of the biofilms were determined as described by Lazarova et al. (1997).

\section{Statistics}

Statistical analyses include paired $t$-tests and one-way analysis of variance. Analyses were performed on $\log _{10}$ transformed data for the cfu and the total cell counts. Statistical calculations were based on confidence levels equal or higher than $90 \%$.

\section{RESULTS AND DISCUSSION}

The flow cell reactors described in Materials and Methods were used in several experiments in order to verify whether this system could monitor changes in growth, accumulation and respiratory activity of biofilms in response to turbulent and laminar flow regimes, for different types of biofilms in laboratory and industrial conditions.

The first set of biofilm growth experiments on stainless steel plates was performed in well-defined laboratory conditions with the concomitant evaluation of some biofilm parameters. The results presented in Fig. 2(a) describe typical biofilm growth curves as measured by under two flow regimes. The differences in flow rate did not seem to significantly influence the accumulation of the biofilm. Nevertheless, the higher thickness was obtained at low flow velocity, particularly for longer biofilm formation times ( $>7 \mathrm{~d}$ ). In general, higher flow rates give rise to biofilms strongly adhering to the surface (Vieira et al. 1993; Bott 1995). This may explain the more stable trend of the biofilm growth curve obtained under turbulent flow. The plateau thickness of this biofilm is about $20 \mu \mathrm{m}$. Biofilms grown under turbulent flow regime had a visible exopolymeric matrix that was not apparent under laminar conditions, as revealed by scanning electron microscopy (S.E.M.) micrographs (data not shown). The EPS matrix plays an important role in protecting bacteria from external hostile conditions such as harmful substances (Gilbert and Brown 1995) and hydrodynamic stresses (Christensen and Characklis 1990).

In order to study the biofilm activity, the respiration rate of the biofilm bacteria was measured. The respiratory behaviour of the biofilms (Fig. 2b) was significantly different $(P=0 \cdot 05)$ 

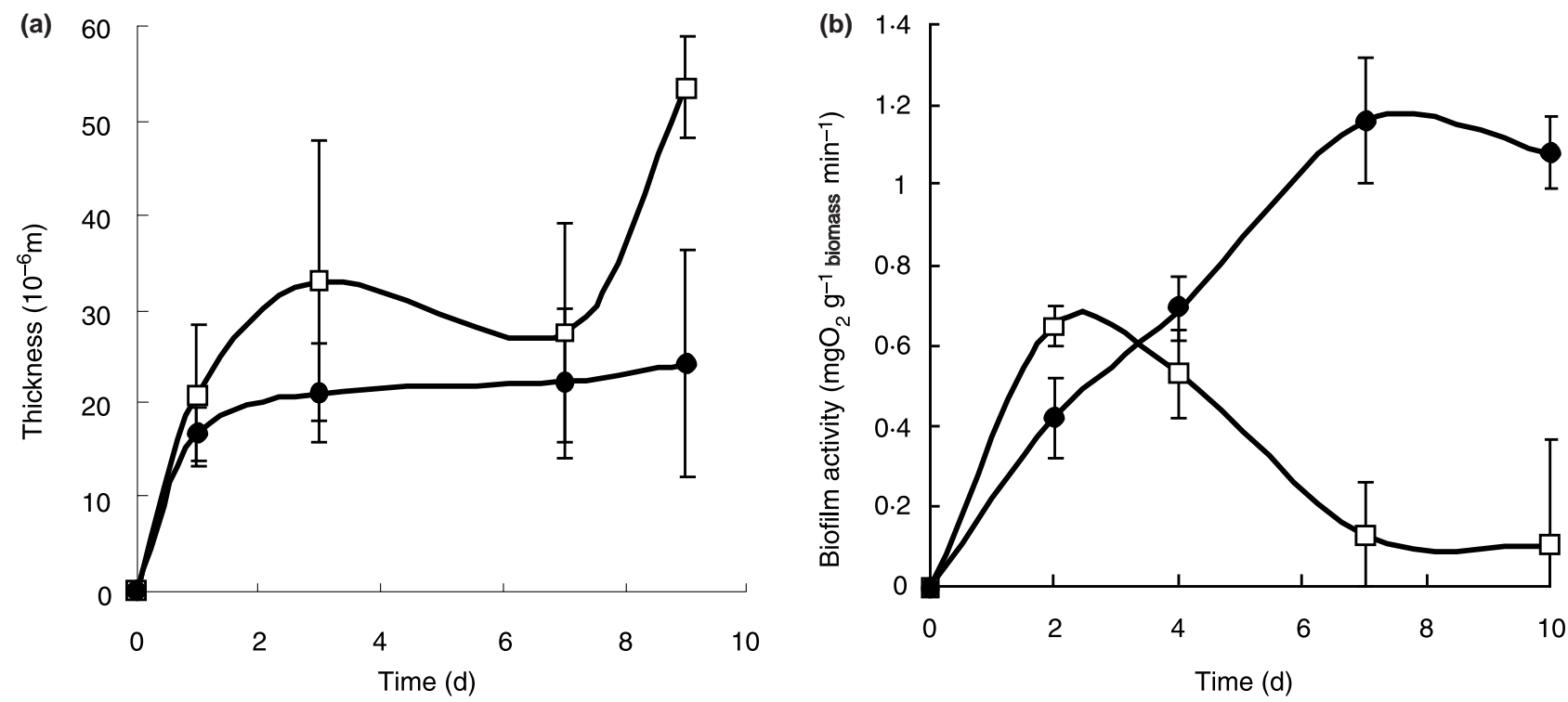

Fig. 2 Thickness (a) and respiratory activity (b) of Ps. Fluorescens biofilms grown under turbulent (๑) and laminar ( $\square$ ) flow regimes vs. time. Bars represent the standard deviation of the mean

according to the flow conditions tested. The biofilm presented a higher respiratory activity when developed under turbulent flow condition than under laminar flow.

The flow cell reactor was also found to be a good tool in following biofilm growth in a semicontrolled system where tap water was used as inoculum. Figure 3 shows the building of biofilm on Perspex plates as measured by biofilm cfu and total cell densities and by reactor effluent cfu concentration. A pseudo-steady state was only reached after $6 \mathrm{~d}$ for the biofilm density, while the cfu concentration in the reactor effluent

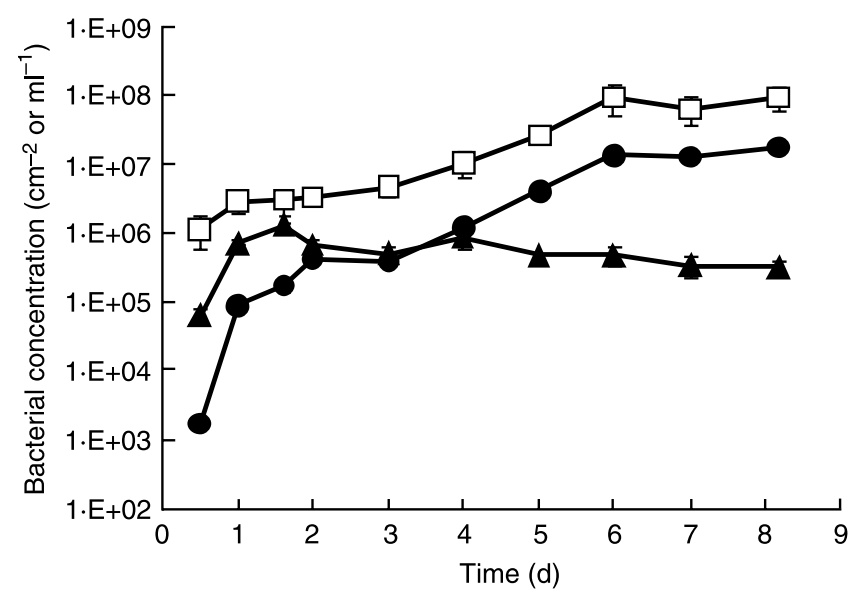

Fig. 3 Tap water biofilm growth on Perspex plates vs. time as measured by cfu and total cell densities. $(\square)$, total cell in biofilm; $(\boldsymbol{O})$, cfu in biofilm; $(\boldsymbol{\Delta})$, cfu in reactor effluent. Bars represent the standard deviation of the mean reached a maximum in 2-3 d, then decreased slightly to attain a plateau. Therefore it appears that the biofilm development cannot be followed by effluent bacterial concentration measurements. This emphasizes the usefulness for reactors allowing direct and real-time evaluation of biofilm growth.

In another set of experiments the flow cell reactor was used to develop biofilms in industrial conditions through the circulation of real 'white water' of a paper mill taken through a side-stream in the industrial plant. Figure 4 presents typical biofilm growth curves for both laminar and turbulent flows,

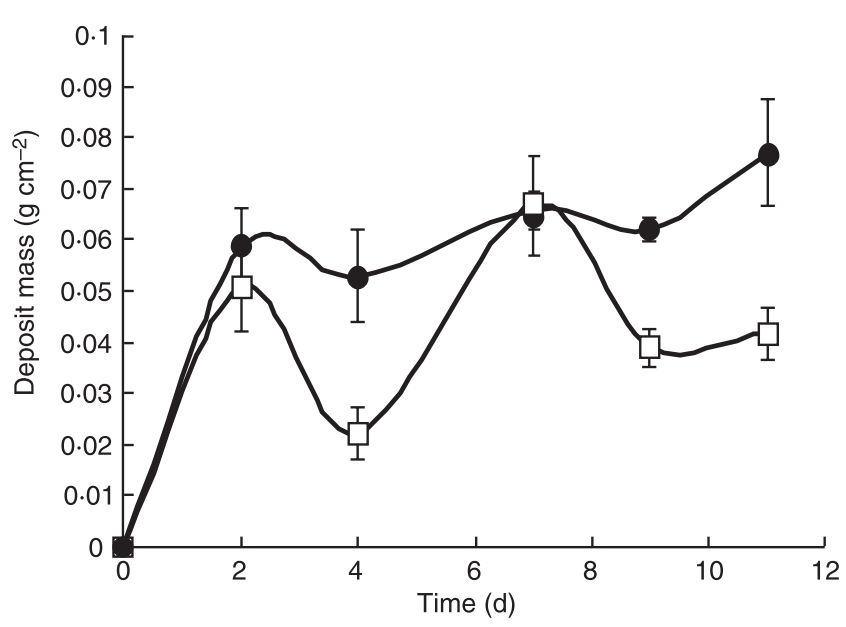

Fig. 4 Industrial biofilm growth on stainless steel vs. time for turbulent $(\boldsymbol{O})$ and laminar $(\square)$ flow regimes as measured by deposit mass. Bars represent the standard deviation of the mean 
the latter presenting a more stable trend than the former. The better stability of the biofilm grown under turbulent condition is confirmed and could be again explained by the presence of an EPS matrix.

\section{CONCLUSIONS}

The flow cell reactor proposed here proved to be very useful in monitoring biofilm development in laboratory and industrial conditions, since each biofilm-covered plate can be easily removed without stopping the flow for off-line, nondestructive and destructive biofilm analysis. The parameters monitored during biofilm growth, in laboratory well-defined conditions or in industrial environments, clearly outlined typical and reproducible biofilm growth curves. The versatility of this flow cell should be emphasized since it can be easily adapted or redesigned according to the technique to be used for biofilm characterization, as it happens with specific samples for CLSM or S.E.M. The adaptation needed in such cases is basically the scale up (or scale down) of the flow cells and the slides. Various types of material can be used for the manufacturing of the slides.

\section{ACKNOWLEDGEMENTS}

This work was supported by Instituto de Biotecnologia e Química Fina (IBQF). The authors thank Manuel A. G. dos Santos for the construction of the flow cell reactors.

\section{REFERENCES}

Block, J.C., Haudidier, K., Paquin, J.L., Miazga, J. and Lévi, Y. (1993) Biofilm accumulation in drinking water distribution systems. Biofouling 6, 333-343.

Bott, T.R. (1995) Biological growth on heat exchangers surfaces. In Fouling of Heat Exchangers ed. Bott, T.R. pp. 223-286. Amsterdam, The Netherlands: Elsevier.
Brown, L.F. and Fogler, H.S. (1986) Distributions of residence time for chemical reactors. In Elements of Chemical Reaction Engineering ed. Fogler, H.S. pp. 629-679. NJ, USA: Prentice Hall.

Chen, C.-I., Griebe, T. and Characklis, W.G. (1993) Biocide action of monochloramine on biofilm systems of Pseudomonas aeruginosa. Biofouling 7, 1-17.

Christensen, B.E. and Characklis, W.G. (1990) Physical and chemical properties of biofilms. In Biofilms eds Characklis, W.G. and Marshall, K.C. pp. 93-130. NY, USA: John Wiley \& Sons, Inc.

Costerton, J.W., Cheng, K.J., Geesey, G.G., Ladd, T.I., Nickel, J.C., Dasgupta, M. and Marrie, T.J. (1987) Bacterial biofilms in nature and disease. Annals of Reviem of Microbiology 41, 435-464.

Gilbert, P. and Allison, D.G. (1993) Laboratory methods for biofilm production. In Microbial Biofilms: Formation and Control eds Denyer, S.P., Gorman, S.P. and Sussman, M. pp. 29-49. London: Blackwell Science.

Gilbert, P. and Brown, M.R.W. (1995) Mechanisms of the protection of bacterial biofilms from antimicrobial agents. In Microbial Biofilms eds Lapin-Scott, H.M. and Costerton, J.W. pp. 118-130. Cambridge: Cambridge University Press.

Jones, K. and Bradshaw, S.B. (1996) Biofilm formation by Enterobacteriaceae: a comparison between Salmonella enteritidis, Escherichia coli and a nitrogen fixing strain of Klebsiella pneumoniae. Fournal of Applied Microbiology 80, 458-464.

Lazarova, V., Nogueira, R., Manem, J. and Melo, L. (1997) Control of nitrification efficiency in a new biofilm reactor. Water Sci. Technology 36, 31-41.

Ludensky, M.L. (1998) An automated system for biocide testing. Fournal of Industrial Microbiology and Biotechnology 20, 109-115.

Mittelman, M.W., Kohring, L. and White, D.C. (1992) Multipurpose laminar-flow adhesion cells for the study of bacterial colonization and biofilm formation. Biofouling 6, 39-51.

Nivens, D.E., Palmer, R.J. and White, D.C. (1995) Continuous nondestructive monitoring of microbial biofilms: a review of analytical techniques. Fournal of Indus Microbiology 15, 263-276.

Vieira, M.J., Melo, L. and Pinheiro, M.M. (1993) Biofilm formation: hydrodynamic effects on internal diffusion and structure. Biofouling 7, 67-80. 